Revista

\title{
Multi-Ensayos
}

Vol. 4, $\mathrm{N}^{\circ} 7$

ISSN: 2412-3285

https://multiensayos.unan.edu.ni

DOI: https://doi.org/10.5377/multiensayos.v4i7.9486

\section{Importancia del proyecto de vida, su relación con la motivación y la satisfacción laboral}

\section{Importance of the life project, its relationship between job satisfaction and motivation}

Orbelina Rodríguez González ${ }^{1}$

Recibido: 28 de febrero de 2018, Aceptado: 18 de octubre de 2018

\section{RESUMEN}

El presente ensayo contiene conceptos y aspectos importantes sobre: el proyecto de vida, la motivación y la satisfacción laboral; así como algunas experiencias de los estudiantes de I año de la carrera de Administración de Empresas al elaborar su proyecto de vida; el cual les permitió darse cuenta de lo importante de saber qué es lo que quieren alcanzar en el fututo y qué están haciendo para lograrlo, de igual manera, valorar el apoyo que han recibido de las personas que tienen a su alrededor.

Palabras claves: proyecto de vida; motivación; satisfacción laboral.

\begin{abstract}
This essay comprehends important concepts and aspects about: the life project, job satisfaction and motivation, as well as some first year Business Administration students' experiences when preparing their life project, which allowed them to realize the importance of knowing what they want to achieve in the future and what they are doing to achieve it, also they valued the support they have received from the people they have around.
\end{abstract}

Keywords: life Project; motivation; job satisfaction.

1 Docente del Departamento de Ciencias Económicas y Administrativas, UNAN-Managua/FAREM-Estelí. Correo electrónico: rodriguezgonzalezorbelina@gmail.com

Copyright (c) 2018 Revista Multi-Ensayos. 


\section{INTRODUCCIÓN}

Este documento presenta algunos aspectos importantes sobre el proyecto de vida, su relación con la motivación y la satisfacción laboral. En la medida en que la persona tiene definido qué es lo que quiere alcanzar en su vida, en esa medida estará motivada cada vez que ascienda a una nueva meta. Si bien es cierto la motivación viene del exterior, también tiene que ver la parte interna de la persona; por más que se trate de motivar a alguien que internamente está mal, no se va lograr hacerlo.

El objetivo de este escrito es determinar la importancia que tiene este tema para un estudiante de la carrera de Administración de Empresas, en vista que, en la asignatura de Administración II, el estudiante debe de tener claro que la planeación es una de las funciones administrativas más importantes para toda empresa, sea esta pública o privada; porque a través de ella se sabe cuál es la misión, visión y objetivos de la empresa. De la misma forma, el ser humano debe de tener claro cuáles son sus metas a corto y largo plazo. En ese sentido, un ejercicio sencillo para ello es elaborar su propio proyecto de vida.

\section{DESARROLLO}

En la asignatura Administración II, según se orienta en el programa de asignatura, se impartió un tema denominado análisis de los diferentes modelos del comportamiento, cuyo objetivo es analizar el valor que tienen los modelos del comportamiento organizacional. Uno de los subtemas es la relación del clima laboral con otras variables (entre estas esta la motivación y la satisfacción laboral). Dichos temas son muy importantes para ser estudiados en todas las carreras, pero principalmente en la carrera de Administración de Empresas.

Kossen, (1995) define motivación como: "los impulsos diferentes internos o las fuerzas ambientales alrededor, que estimulan a los individuos a comportarse de una forma específica. Motivar es generar el desplazamiento de una actitud hacia otra o de un comportamiento hacia otro distinto".

Las instituciones y las organizaciones pueden hacer mucho para mantener a sus integrantes con buenos niveles de motivación. No obstante, se debe estar consciente de que no todas las personas reaccionan a los estímulos de la misma manera. De acuerdo a Víktor Frankl (1991), la persona es capaz de escoger la actitud personal con la que enfrenta su realidad, es una decisión interna, por ello, la motivación viene del interior del individuo. Es muy importante tomar en cuenta que la motivación de las personas es un fenómeno que proviene del propio individuo. Es decir, que lo que motiva a una persona puede que no sea fuente motivacional para otra persona. Otro aspecto a tratar es la satisfacción laboral; que está íntimamente relacionada con la motivación.

Guillen y Guil (2000), agrupan las conceptualizaciones de satisfacción laboral de la siguiente manera:

a. "Como estado emocional. (Locke, 1976) la define como estado emocional positivo o placentero resultante de la percepción subjetiva de las experiencias laborales de la persona.

b. Como actitud generalizada ante el trabajo. (Peiró, 1984) teniendo en cuenta que las actitudes responden a un modelo tridimensional: dimensión afectiva, cognitiva y comportamental. 
c. Como actitud afectiva. (Newstron y Davis, 1993) distinguen dos modelos: Modelo unidimensional. Actitud hacia el trabajo en general. Modelo Multidimensional. Contempla distintos aspectos o dimensiones concretos del trabajo". Aun, cuando muchos autores no realizan.

Un trabajador puede desarrollarse como persona a través del propio trabajo y encontrarse satisfecho con la ocupación que desempeña, aquí entra en juego lo que es el proyecto de vida.

Del latín proiectus, el concepto de proyecto nombra el conjunto de actividades coordinadas e interrelacionadas que buscan cumplir con un objetivo específico. En este sentido, podría decirse que un proyecto de vida es la dirección que una persona marca para su propia existencia.

Al definir un proyecto de vida, las personas podrán defender lo que piensan, sus intereses y formarse un carácter menos vulnerable al medio. La elaboración de un proyecto de vida debe considerar aspectos tales como: el entorno y conocimiento de la persona; la búsqueda de información para satisfacer las inquietudes y posibilidades que nos rodean para alcanzar las metas propuestas; y la flexibilidad, que no debe faltar, pues los seres humanos poseen múltiples intereses, habilidades y la capacidad de rectificar, además los resultados no dependen sólo de la persona.

Pero ¿cuál es la relación entre el proyecto de vida, la motivación y la satisfacción laboral? En la medida en que la persona sabe qué es lo que quiere alcanzar o hacia donde dirige sus actividades (el proyecto de vida) en esa medida sabrá si en el transcurso del camino está alcanzando sus metas propuestas y en esa medida estará motivada y con deseos de seguir adelante. Para ello, el medio ambiente interno de la organización le debe de brindar las condiciones adecuadas para que se sienta satisfecho en su centro de labores.

Tomando como referencia la teoría antes expuesta, en la UNAN-Managua, FAREM-Estelí, se realizó un trabajo con los estudiantes, a quienes se les orientó que elaboraran de manera individual su proyecto de vida y esto permitió conocerlos más a fondo. Se les compartió que todo estudiante de Administración de Empresas debe de tener bien definido su proyecto de vida, y que como universitarios que son, no pueden decir "no tengo un proyecto de vida.- vivir al día ante tinieblas y oscuridad". El proyecto de vida suele ser el que guiará toda la vida; de ahí la importancia de ir actualizándolo permanentemente, con base a las metas que se van consiguiendo y a las nuevas situaciones que se presentan.

Una vez introducido el tema, el punto de partida para la elaboración del proyecto de vida fue que el estudiante lograra lo siguiente: conocer su situación (fortalezas y debilidades), la autobiografía es decir: ¿Quiénes han sido las personas que han tenido mayor influencia en su vida y de qué manera?, ¿Cuáles han sido sus intereses desde la edad temprana?, ¿Cuáles han sido los acontecimientos que han influido en forma decisiva en lo que se ha alcanzado?, ¿Cuáles han sido los principales éxitos y fracasos?, rasgos de la personalidad (aspecto físicos, relaciones sociales, vida espiritual, vida emocional, aspectos intelectuales, y aspectos vocacionales, hacia dónde va( ¿Cuáles son sus sueños?, realidades, impedimentos y que hará para alcanzar sus metas.

Fue muy gratificante ver los videos elaborados por los estudiantes. En ellos resumieron lo que ha sido su vida hasta el momento, las dificultades que se les han presentado y lo que esperan alcanzar en el futuro. 
A continuación se detalla la experiencia de los estudiantes al elaborar por primera vez su proyecto de vida:

Luz del Carmen; expresa "Es increíble hacer un recuento de todo lo vivido, de todo lo compartido, de los logros y dificultades, de saber dónde estamos y para dónde vamos, poder contar un poco de mi vida mis metas, los cuidos y mimos de mi familia. Siempre he luchado por ser una excelente estudiante y con esfuerzo y dedicación lo he logrado. Una de mis metas era concluir mi secundaria y lo logré con honores. Ahora que estoy en la universidad tengo nuevas metas que con el apoyo de mi Dios y mi familia lo voy a lograr. Llegando al final diré que mis nuevas metas a corto plazo son seguir siendo una excelente estudiante, terminar mi carrera y poder graduarme y desempeñarme como una administradora de éxito".

Marlon; "Nos sirve de guía para tener un horizonte".

Karen; "El haber realizado mi proyecto de vida ha sido una experiencia muy bonita, me sirve para valorar lo que he realizado en mi vida, todo lo que he luchado para llegar donde estoy, he disfrutado cada etapa de mi vida, a medida que crecía me daba cuenta de lo importante que era para mí hacer sentir orgullosos a mis padres. En la secundaria empezaron mis retos y obtuve algunos de mis reconocimientos, me bachilleré con un excelente promedio. Algunos problemas me impidieron ir a la universidad durante dos años en los que estuve trabajando, actualmente estudio por la mañana y trabajo por la tarde. Mis planes a corto plazo son: culminar mi carrera con excelente calificaciones, conseguir un trabajo estable. Estoy segura de que en el transcurso de mi vida se me presentaran obstáculos, no será fácil, pero con la ayuda de Dios lo lograré”.

Margarita; "Es muy importante que todo estudiante tenga un proyecto de vida que sirva de guía”.

Bayara; "Este me va servir para que tenga mis metas tanto a corto como a largo plazo. Mi familia es mi mayor motivación para seguir adelante, Dios mi gran guía, con Él todo, sin Él nada. Haber estudiado en un colegio religioso ha sido mi mayor experiencia. Soy una persona positiva, alegre y sociable, me gusta salir de la rutina y experimentar cosas nuevas. Amo saber que con lo poco que poseo puedo ayudar al que necesite. Una de mis metas es culminar mi carrera y desempeñar mi profesión con mucho entusiasmo, ser una gran administradora, formar una familia y ser una buena esposa así como también una gran madre”.

Hector; "El éxito en la vida depende en gran parte de las metas que tengamos".

Yumari; "Me he dado cuenta que para llegar donde estoy se me han presentado muchas dificultades; pero gracias a Dios las he superado y espero cumplir en el futuro todos mis anhelos, ya que tengo una hija por la cual debo de luchar para seguir adelante y darle lo mejor. Esto lo puedo lograr con una buena preparación".

Jennifer; "El proyecto de vida ha sido como hacer una biografía de mi vida, saber quién soy, que tengo metas por cumplir".

Eskarleth; "Me sirve para dar sentido a mi vida y es como una indicación direccional".

Luz Samari; "Me he dado cuenta que mi vida tiene sentido, que tiene dirección". 


\section{CONCLUSIONES}

Un joven no puede dar consistencia a su proyecto si no tiene consciencia del tiempo vivido y de su duración. Tiene que ser capaz de anticipar su porvenir. Por eso, le es necesario haber descubierto lo que él es al presente; su identidad. El lazo entre el presente y el futuro lo da la fidelidad a sí mismo. En efecto, el dinamismo de la vida se traduce en el reconocimiento del sentido de la vida y el significado que le dan los acontecimientos.

Este ejercicio es muy interesante; porque le permite al estudiante darse cuenta de todo lo que ha pasado para llegar donde está, quiénes han formado parte de sus logros, algunas situaciones tristes que han tenido que enfrentar y lo más importante; para dónde van y qué deben de hacer para alcanzar esas metas que se proponen.

\section{BIBLIOGRAFÍA}

Guillén, C. y Guil R. (2000). Psicología del trabajo para relaciones. Madrid, España: McGraw Hill.

Kossen (1195). Recursos Humanos en las Organizaciones. Madrid, España: Editorial Universidad Iberoamericana. 